Editorial

\section{To doxycycline with love}

Abbreviations: MMP, matrix metalloproteinases; KCS, keratoconjunctivitis sicca

\section{Editorial}

After more than 60 years of the discovery it is still used in our daily practice, Doxycycline as we know is a long-acting second generation synthetic tetracycline derivative with similar antimicrobial activity with somehow less side effects, act on bacterial ribosomes, preventing them from effectively translating mRNA into vital proteins, and inhibits matrix metalloproteinases (MMP) such as type 1 collagenase in studies on wound healing and tissue remodeling.

Over time they found other treating abilities of this fine medication especially of real importance to us as ophthalmologists, as for many drugs that were incidently discovered to have an astonishing effect to treat diseases that once were difficult to treat. Iovieno A et al., ${ }^{1}$ suggested that a 4 weeks treatment with doxycycline significantly improved symptoms and signs in patients with chronic blepharitis in association with a decrease in MMP-9 activity.

I was using doxycycline in treating some cases of chronic posterior blepharitis that are resistant to conventional treatment with topical drugs and lid hygiene especially those with the plan to undergo an ocular surgery, I had a patient that I was forced to treat him for more than three months with doxycycline before operating on him for cataract surgery with great results.

Keratoconjunctivitis sicca (KCS) known also as the dry eye syndrome 1 out of 7 individuals aged 65 to 84 years reports symptoms of dry eye often or all of the time ${ }^{2}$ and these individuals can benefit greatly from doxycycline treatment, I was prescribing it along with topical lubrication drops for mostly all of my patients with KCS although some of them complain of one or two of its side effects, they all benefited greatly from this combination. Many Physicians tried to find other uses or other ways of benefiting from doxycycline in various forms some succeeded one of those was Zhang $Z$ et al. ${ }^{3}$ Who found that topical doxycycline showed clinical improvements and alleviated ocular surface inflammation on BAC-induced mouse dry eye, suggesting a potential as an anti-inflammatory agent in the clinical treatment of dry eye.

Doxycycline's therapeutic value depends upon its chelating properties of the metal ions that are catalytically and structurally

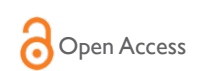

CrossMark
Volume I Issue I - 2014

\author{
Hassan F Alkwikbi \\ Department of Ophthalmology, Prince Salman Hospital, Saudi \\ Arabia
}

Correspondence: Hassan FAlkwikbi, Department of Ophthalmology, Consultant Ophthalmology Surgeon, Prince Salman Hospital, Ministry of Health, Riyadh, Saudi Arabia, Tel 00966-I I-43 I I 100,Email hsn_dr@hotmail.com

Received: August 16,2014 | Published: August 19, 2014

essential and this depends on its concentration at the ocular surface, ${ }^{4}$ which is impressively high.

That is to remind us that the solution or the treatment of some diseases with no cure currently might be under our noses, we need only to rediscover.

\section{Acknowledgments}

None.

\section{Conflicts of interest}

Author declares that there is no conflict of interest.

\section{References}

1. Iovieno A, Lambiase A, Micera A, et al. In vivo characterization of doxycycline effects on tear metalloproteinases in patients with chronic blepharitis. Eur J Ophthalmol. 2009;19(5):708-716.

2. Schein OD, Muñoz B, Tielsch JM, et al. Prevalence of dry eye among the elderly. Am J Ophthalmol. 1997;124(6):723-728.

3. Zhang Z, Yang WZ, Zhu ZZ, et al. Therapeutic effects of topical doxycycline in a benzalkonium chloride-induced mouse dry eye model. Invest Ophthalmol Vis Sci. 2014;55(5):2963-2974.

4. Smith VA, Cook SD. Doxycycline-a role in ocular surface repair. $B r J$ Ophthalmol. 2004;88(5):619-625. 